\title{
Desinformacion y pandemia. La nueva realidad
}

AUTORES / AUTHORS

Raúl Magallón Rosa

Madrid, Pirámide, 2020, 151 pp.

https://www.edicionespiramide.es/libro.php?id=6503695

Esta obra parte del desconcierto, se escribe inmersa en él. Un desconcierto provocado por la pandemia de Covid-19, pero también por la cobertura mediática y las reacciones en cadena que se fueron produciendo desde la escalada de casos y el posterior confinamiento. A modo de resumen inicial, valga destacar que el análisis contenido en el escrito de Raúl Magallón Rosa se centra en el «tsunami de desinformación» sobre la pandemia, que golpeó durante meses (aún lo hace) en medios de comunicación, redes sociales y sitios web.

El análisis desarrollado por Raúl Magallón parte de una situación de extrema actualidad, que se fue construyendo con el propio discurrir de los acontecimientos. Responde a la urgencia de un contexto informativo que se vio desbordado por los sucesivos hechos acaecidos, pero también por el número de actores y discursos que proliferaron en el marco de un público con mayor receptividad que en otros momentos. Una mayor receptividad a las informaciones por parte de la población, por el propio estado de confinamiento en el que se encontraba, provocado por una «mediatización extrema» (pág. 13). Este escenario lleva al autor a emprender un exhaustivo análisis del proceso de «desinformación» vivido durante la pandemia, sumergiéndose en el «ecosistema informativo» (pág. 13), pero trascendiendo las meras implicaciones del momento para acceder a ciertas prácticas de desinformación sistemática, que se están extendiendo cada vez por más espacios y sobre más temas.

Las primeras semanas de la pandemia, cuando aún ni siquiera recibía ese nombre pero los casos se multiplicaban por Europa diariamente, marcaron el inicio de noticias e informaciones que empezaban a circular por redes sociales y medios de comunicación. La necesidad de informarse sobre lo que estaba aconteciendo en diferentes lugares, pero también de las posibles vías de contagio, posibles paliativos para la enfermedad o incluso las medidas que se adoptarían para frenar su expansión, marcaron el inicial interés de un público que nunca había asistido a una situación de emergencia sanitaria como la vivida. Estas primeras semanas fueron prolíficas en especulaciones, teorías e informaciones poco contrastadas, hasta el punto de ser más urgente «detener la desinformación que dar una información - parcial e incompleta- de la evolución de la crisis» (pág. 14).

Una gran demanda de información, generó una gran oferta de «bulos». Partiendo de las numerosas noticias falsas y bulos que circularon por diferentes medios, propagándose a gran velocidad gracias a las redes sociales. Ante ello el autor desarrolla una categorización de los 
mismos con el fin de agruparlos en relación con el aspecto concreto en el que se centraban. Nos habla así de bulos en relación con el «contagio», la «prevención», las «medidas adoptaban en la lucha contra la pandemia y para paliar sus efectos», y una última categoría bajo el nombre de «otros» como "cajón de sastre de diferentes problemáticas» (pág. 21). Los bulos que circularon durante la pandemia iban desde remedios caseros para curar la Covid-19, hasta estafas y aparentes predicciones de la situación de pandemia mundial.

La propagación de la desinformación se hacía cada vez más preocupante a medida que avanzaba la pandemia, algo de extrema importancia si tenemos en consideración la advertencia que el propio autor rescata de Carl Miller (2017) a propósito de la veracidad que las personas le confieren a «expresiones espontáneas de las redes sociales» (pág. 37), frente a opiniones expertas divulgadas por medios de comunicación. Muestra de desconfianza en los medios tradicionales, pero también de legitimación de informaciones no contrastadas, a menudo simplemente opiniones personales. A esta situación se suma el hecho de que lo censurado adquiere una mayor atención por parte del público, sintiendo que se le está ocultando información de forma deliberada. El público concentra su atención sobre esa noticia (pág. 27), independientemente de que la información censurada sea falsa o irrelevante. El panorama en su conjunto mostraba un complejo tablero en el que cualquier movimiento desembocaría en una oleada de reacciones en cadena, fundamentalmente en redes sociales, uno de los canales principales a través de los cuales la población accede a la información.

Si la actualidad informativa ya estaba marcada por las «métricas» (pág. 64) que pueden arruinar el trabajo periodístico, la pandemia permitió ver con mayor claridad cómo ciertos contenidos crecían en visualizaciones y popularidad sin necesariamente ser una información contrastada e incluso cierta. La búsqueda de información por parte de la población, llevó a seguir hilos informativos, en ocasiones alejados de los datos contrastados que se estaban difundiendo por los canales tradicionales. Canales tradicionales que a su vez vieron difuminada su información y su alcance debido a la polarización política en donde, «de una sobreexposición informativa se acabaría pasando a una fatiga» (pág. 76). La población, en este mar de informaciones cruzadas, buscaba navegar hacia explicaciones plausibles a lo que estaba aconteciendo, con frecuencia distantes de toda explicación científica y en ocasiones incluso racional.

La búsqueda de unidad para hacer frente a la pandemia, tanto en España como en otros países, se vehiculó a través de un lenguaje «belicista», algo que «ayudó a la polarización y a la división» (pág. 131), como remarca el autor siguiendo la línea de Alba Rico y Herrero (2020). Se habló así de guerra contra la pandemia, como pretendido lenguaje aglutinador. En pleno contexto de visiones encontradas, de numerosas fuentes informativas en disputa, desconfianza y desconcierto, un lenguaje en términos de «guerra» contra la pandemia contribuyó a dividir aún más las opiniones, pero también las estrategias que en ese marco se pensaban como forma más eficiente de hacerle frente.

El contexto de nueva normalidad, trae consigo lo que el autor denomina «informalidad» (pág. 117), en el que se hace urgente debatir sobre las regulaciones de la información, para con ello evitar caer en posibles restricciones de la libertad de prensa, o en la exaltación de las fuentes oficiales. La importancia de un equilibrio ha quedado patente.

Las redes sociales han jugado un papel protagonista, tanto por ser una vía de acceso a la información para buena parte de la sociedad como por el hecho de haber desarrollado 
mecanismos de control para determinadas publicaciones. Por otro lado, la publicidad y la promoción de determinados contenidos llevaron también a que la rentabilidad pasara a un primer plano. Nuevamente el equilibrio vuelve a aparecer como una de las claves para no generar un mayor desconcierto dentro del público en general.

Esta obra tiene una gran importancia por atender a una preocupación de primer orden, en un contexto conformado por dos elementos clave como son el miedo y la sobreexposición a versiones inconexas de informaciones no contrastadas. Estos dos elementos se presentan como el caldo de cultivo ideal para la promoción de una desinformación cada día más preocupante por las implicaciones vitales que generan en la población. Implicaciones como falta de seguridad, desconfianza, confusión, que llevan a una mayor inestabilidad.

En este libro el lector podrá acceder a las principales claves para hacer frente a la desinformación, partiendo de un análisis apegado a la actualidad, a las vías por donde se propagan los «bulos» y por supuesto, a las estrategias que se han puesto en marcha para poder frenarlos. En calidad de lectores y consumidores de información en general, todos estamos sujetos a los vaivenes comunicativos, la obra de Raúl Magallón nos abre los ojos ante este lado oscuro de la información que nos llega, para ser críticos y reflexivos.

\section{Bibliografía}

ALBA RICO, Santiago y HERRERO, Yago (2020). “¿Estamos en guerra?». Ctxt.es. Contexto y acción, 22 de marzo. Recuperado de: http://ctxt.es/es/20200302/Firmas/31465/catastrofe-coronavirusguerra-cuidados-ciudadanos-ejercito-alba-rico-yayo-herrero.htm

MILLER, Carl (2017). «The big business of disinformation». Wired, 10 de junio. Recuperado de: https:// www.wired.co.uk/article/carl-miller-disinformation-gets-commercialised

Por Dra. Ivana Belén Ruiz-Estramil

Universidad Pública de Navarra

@ ivanabelenrues@gmail.com (iD) 0000-0002-7696-2770 